\title{
For 2013 - Twice the Number of Articles and Four Times the Subscribers
}

In 2012, the International Centre for Diffraction Data (ICDD) changed publishers of the Powder Diffraction journal (PDJ) to Cambridge University Press. We are excited to share some publishing statistics from the first six months with our new partner.

\begin{tabular}{lrr}
\multicolumn{1}{c}{ Number of Subscriptions } & \\
& December 2011 & October 2012 \\
\hline Consortia & 991 & 1,650 \\
Research4Life & 0 & 2,500 \\
Total Subscriptions & $\mathbf{9 9 1}$ & $\mathbf{4 , 1 5 0}$
\end{tabular}

We also saw a significant increase in the number of abstract views and article downloads.

\begin{tabular}{lrr}
\multicolumn{2}{c}{ Abstract Views and Article Downloads } \\
& December 2011 & October 2012 \\
\hline Abstract Views & 6,572 & 9,738 \\
Article Downloads & 800 & 3,438
\end{tabular}

As shown in Figure 1, the new subscription base is global. Our paid subscriptions, including print, online, and consortia have increased $66 \%$.

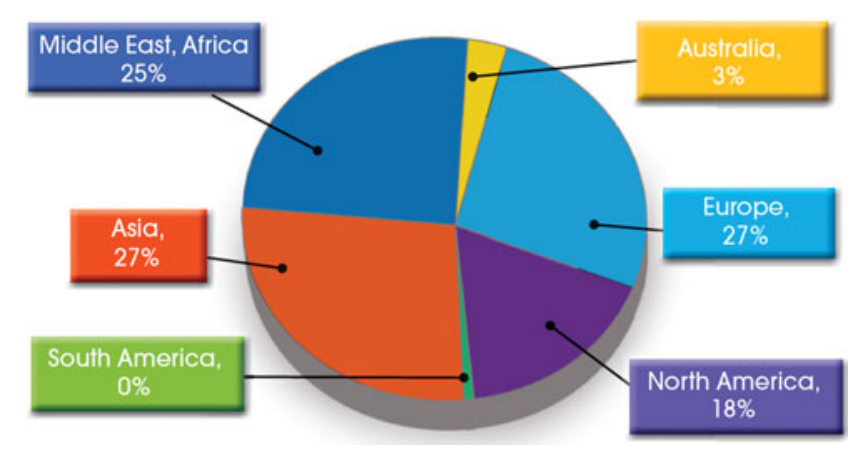

Figure 1. Paid Subscription Base by Geographic Region

There is no better time than now to subscribe to, write for, and advertise in PDJ! In addition to our regular articles, we look forward to bringing you the best from the Denver X-ray Conference, European Powder Diffraction Conference (EPDIC) proceedings and select papers from the $11^{\text {th }}$ National Conference on X-ray Diffraction held in Changchun, China.

Nicole M. Ernst Boris Managing Editor, Powder Diffraction 